NOTAS

NOTES

ANMERKUNGEN 



\title{
COSTUMBRE VERSUS LEY: SOBERANÍA DEL PUEBLO VERSUS SOBERANÍA DEL PARLAMENTO
}

\author{
Héctor ÁlVAREZ García \\ Profesor Ayudante Doctor de Derecho Constitucional \\ Universidad Pablo de Olavide \\ balvgar@upo.es
}

\section{EL DERECHO CONSUETUDINARIO}

La costumbre o Derecho consuetudinario ${ }^{1}$ es el «criterio jurídico de la masa popular» ${ }^{2}$ : ratio vivens. El sentimiento jurídico del pueblo es la primera y natural fuente material del Derecho ${ }^{3}$, del que ha brotado la costumbre desde la noche de los tiempos. El derecho popular «es fundamentalmente un discurso ideológico, razón por la cual, de manera continua, se encuentra sometido a cambios, siendo capaz de modificarse rápidamente para adaptarse a las necesidades que surgen en cada comunidad. Lo que permite hablar, a diferencia de lo que sucede con la ley, mucho más rígida, de la flexibilidad del Derecho consuetudinario» ${ }^{4}$.

«Al igual que para éste [el lenguaje], para el Derecho no hay un solo instante de reposo. El mismo movimiento, el mismo desenvolvimiento se veri-

${ }^{1}$ La expresión ius consuetudinarium no aparece en la obra de Justiniano, sino que su paternidad hay que atribuírsela a un glosador de la Escuela de Bolonia, probablemente Martinus. Cfr. A. Gouron, «Sur les origines de l'expression "Droit coutumier"», Glossae. Revista de Historia del Derecho Europeo, núm. 1 (1988), pp. 179-188.

2 J. M. Pérez-Prendes, Curso de historia del Derecho español, Madrid, Universidad Complutense, 1989 , p. 509.

3 «Tal es la idea que se mantiene comúnmente de la formación primitiva de todo derecho. El derecho, según ella, ha venido al mundo como el idioma, sin esfuerzos ni fatigas, fruto de la acción invisible, inconsciente y pacífica de la fuerza del pueblo» (R. vON IHERING, El espiritu del Derecho romano, Granada, Comares, 1998, p. 307, nota 22).

${ }^{4}$ M. Serna Vallejo, «Costumbre y prescripción: un diálogo entre historiadores, juristas y sociólogos», en S. DE Dios, R. Infante, R. Robledo y E. ToRijano (coords.), Historia de la propiedad, costumbre y prescripción, Madrid, Servicio de Estudios del Colegio de Registradores, 2006, p. 882. 
fica en él que en cualquier otra tendencia del pueblo, y semejante desenvolvimiento está bajo la misma ley de intrínseca necesidad, como cualquier otra primitiva manifestación. El Derecho progresa con el pueblo, se perfecciona con él y, por último, perece cuando el pueblo ha perdido su carácter» ${ }^{5}$.

El Derecho consuetudinario refleja las convicciones jurídicas del pueblo fraguadas en su dilatada práctica cotidiana ${ }^{6}$. No son estáticas, sino dinámicas, porque el Derecho es un fenómeno histórico al servicio de la sociedad, cuyo contenido sustantivo ha de ser modulado en razón de las necesidades y aspiraciones del pueblo:

«La producción del Derecho es siempre un hecho comunitario [que implica] la existencia de una comunidad en el modo de pensar y de hacer. Como una tal comunidad sólo existe dentro de los límites de un pueblo individual, el Derecho real sólo puede producirse dentro de esos límites. Pero esto no implica que no sea al mismo tiempo la exteriorización de una propensión general humana; es decir, que el hecho de que todos los pueblos tengan Derecho no es una mera coincidencia casual. Lo que en verdad ocurre es que el Derecho, como producto del "espíritu del pueblo", puede ser peculiar y exclusivo de cada pueblo o coincidente en varios pueblos, en cuanto es fruto de una propensión general humana» ${ }^{7}$.

El Derecho está inserto en la historia de cada comunidad política. No es fruto de la contingente y arbitraria voluntad de los gobernantes de un país: el legislador no puede crear Derecho ex nibilo ${ }^{8}$, sino que está condicionado y arraigado en la historia, la cultura y la tradición de la nación?

${ }^{5}$ F. K. von Savigny, De la vocación de nuestro siglo para la legislación y la ciencia del Derecho, trad. de A. Posada, Madrid, sin datar, p. 23.

${ }^{6}$ «La costumbre es Derecho no escrito, iniciado, continuado e introducido conforme a la razón por los mores y usos del pueblo o de la mayor parte de éste» (B. SASSOFERRATO, Commentaria super Digesto veteris, 1, 3, 32, citado por M. SERna Vallejo, «Costumbre y prescripción...», op. cit., p. 874).

7 M. Rodríguez Molinero, «Derecho y pueblo en Savigny», Anales de la cátedra Francisco Suárez, núm. 18-19 (1978-1979), pp. 238-239.

${ }^{8}$ G. Wesenberg, Neuere deutche Privatrechtsgeschichte im Rabmen der europäischen Rechtssentwicklung, Lahr, Böhlau Wien, 1954, p. 135, citado por F. GonZÁLEZ VICÉN, «La Escuela Histórica del Derecho», Anales de la cátedra Francisco Suárez, núm. 18-19 (19781979), p. 20.

9 «La escuela histórica admite que la materia del Derecho está dada por todo el pasado de la nación, pero no de una manera arbitraria y de tal modo que pudiera ser ésta o la otra accidentalmente, sino como procediendo de la íntima esencia de la nación misma y de su historia. Después, cada tiempo deberá encaminar su actividad a examinar, rejuvenecer y mantener fresca esta materia nacida por obra de una necesidad interna [F. K. vON SAVIGNY, 
Así pues, el concepto de pueblo es previo y trasciende al conjunto de individuos que habitan en un momento determinado el territorio de un Estado. Es una unidad natural e histórica que liga las generaciones pasadas con las presentes y futuras, singularizado por las manifestaciones del espíritu del pueblo —Derecho, usos, arte, moral, religión, lenguaje, etc.,-— que lo diferencia de otros ${ }^{10}$.

La fuerza creadora del pueblo - «el espíritu del pueblo» o «la conciencia común del pueblo» (Savigny) — es la fuente de la que manan las convicciones jurídicas populares que surgen de forma natural como consecuencia del carácter simbiótico de las relaciones sociales, y que se traduce en que todos los ciudadanos obren o actúen uniformemente ${ }^{11}$. Lo que Ihering denomina «principio de la voluntad subjetiva, que descansa sobre la idea de que el individuo lleva en sí, en su sentimiento jurídico y en su energía la razón de su derecho» ${ }^{12}$ :

«Todo derecho tiene su origen en aquellos usos y costumbres a los cuales por asentimiento universal se suele dar, aunque no con gran exactitud, el nombre de Derecho consuetudinario; esto es, que el derecho se crea primero por la costumbre y las creencias populares, y luego por la jurisprudencia; siempre, por tanto, en virtud de una fuerza interior y tácitamente activa, jamás en virtud del arbitrio de ningún legislador» ${ }^{13}$.

¿Cómo cristaliza la conciencia jurídica del pueblo? A través de dos fuentes formales: la costumbre, que «es la expresión espontánea de la conciencia jurídica popular» ${ }^{14}$, y la ley aprobada por el Parlamento, pero no concebido como fuente material del Derecho que pueda innovar en el ordenamiento jurídico de forma libre e independiente de la voluntad

«Sobre el fin de la Revista de la Escuela Histórica del Derecho», en F. K. von SAvigny et al., La Escuela Histórica del Derecho. Documentos para su estudio, trad. de R. Atard, Madrid, Librería General de Victoriano Suárez, 1908, p. 16 (artículo publicado originalmente en la Zeitschrift für geschichtliche Rechtwissenschaft, t. I, núm. 1)].

${ }^{10}$ Cfr. F. K. von SAvigny, Sistema del Derecho Romano Actual, t. I, Madrid, Centro Editorial de Góngora, 1839-1847.

11 «El nacimiento del Derecho desde el "espíritu del pueblo" es invisible. ¿Quién osaría trazar los caminos por los que una convicción surge, germina, crece, se desarrolla, retoña? [...] Lo que nos es visible es lo que ya ha salido a la luz, es decir, el Derecho una vez surgido de la obscura fragua en que ha sido elaborado, una vez que se nos hace real» (G. F. PucHTA, Institutionem, I, pp. 26-27, citado por F. GonZÁlez VicÉn, «La Escuela...», op. cit., p. 28).

${ }^{12}$ R. vON IHERING, El espiritu..., op. cit., p. 84.

${ }^{13}$ F. K. von Savigny, De la vocación de nuestro siglo..., op. cit., p. 28.

${ }^{14}$ A. Dufour, «F. K. von Savigny y el pensamiento del siglo XVIII», Persona y derecho. Revista de fundamentación de las instituciones jurídicas y de derechos humanos, núm. 8 (1981), p. 17. 
popular, sino que ha de dar expresión articulada a «una convicción jurídica ya existente con certeza o bien ayudando, según el verdadero sentido de la nación, a la fijación de una convicción en trance de constituirse» ${ }^{15}$ :

«Tú, diputado, senador, ministro, eres el súbdito, y el pueblo, el soberano; derecho positivo que verdaderamente sea derecho no hay otro que aquel que el pueblo dicta expresamente en sus hechos al ministro o al diputado, o el que el diputado o el ministro saben adivinar en las elaboraciones más o menos calladas de la opinión: si el pueblo crea una costumbre "fuera de ley" es que su órgano para la función de legislar se distrajo y no vio que existía allí una necesidad demandando plan, regla, para satisfacerse; si el pueblo crea una "costumbre contra ley" es que el legislador, por distracción, por precipitación o por soberbia no comprendió la naturaleza de la necesidad o no quiso comprenderla, y le impuso una norma que no le era adecuada, que le venía ancha, que le venía estrecha o que le era enteramente exótica. Y en ese caso no digamos que el pueblo ha sido infiel a la ley, sino que el legislador ha sido infiel al Derecho: no es el pueblo quien desobedece al legislador, es el legislador quien desobedece al pueblo, único soberano» ${ }^{16}$.

La utilidad de la legislatura reside en que en ocasiones el Derecho alumbrado por la conciencia popular no es lo suficientemente claro, preciso y completo para garantizar la seguridad jurídica. Por ello es necesario que el Parlamento «purgue adecuadamente la costumbre, desvanezca tales dudas e interpretaciones, y ponga en plena evidencia el Derecho real, que es la verdadera voluntad del pueblo, manteniéndolo puro» ${ }^{17}$.

\section{LA POTESTAD LEGISLATIVA}

En la Europa feudal, el atributo más conspicuo del poder real era la administración de justicia, que comportaba la potestad gubernativa («justicia gubernativa») y judicial («justicia judicial») ${ }^{18}$. Por eso la titu-

${ }_{15}$ G. F. Puchta, Institutionem, I, p. 29, citado por F. GonZÁLEZ VicÉN, «La Escuela...», op. cit., p. 33.

${ }^{16}$ J. Costa, El problema de la ignorancia del Derecho, Madrid, Sucesores de Manuel Soler, 1901, pp. 91 y 92.

${ }_{17}$ F. K. vON SAVIGNY, De la vocación de nuestro siglo..., op. cit., p. 32.

18 A. GarCía Gallo, «Alcaldes mayores y corregidores en Indias», en Estudios de Historia del Derecho indiano, Madrid, Instituto Nacional de Estudios Jurídicos, 1972, p. 702. Cfr. ÍD., «La división de competencias administrativas en España en la Edad Moderna», en 
laridad de aquélla fue un problema nuclear en el encaje y ordenación de las relaciones feudo-vasalláticas dentro de la estructura política de los reinos ${ }^{19}$.

La facultad legislativa no era una competencia cualificada del monarca porque el orden jurídico medieval tenía «un valor inmanente, la naturaleza de las cosas, y un valor trascendente, el Dios creador de normas propio de la tradición canónica; uno en absoluta armonía con el otro, según los dictados de la teología cristiana, constituyen un ordo, un ordo iuris. El Derecho es así una dimensión óntica y la ciencia del Derecho, o el Derecho como ciencia, es la percepción o la declaración de ese ordo interno a la realidad, es interpretatio de algo que no se crea por el jurista, sino que más bien se declara o se hace explícito partiendo de un Derecho que está más allá de la pura interpretación, como algo que ella misma presupone» ${ }^{20}$.

La teoría política hegemónica en la Europa occidental durante el Medievo fue la doctrina hierocrática o de las dos espadas. Fundada en la cosmogonía cristocéntrica ${ }^{21}$, se caracterizaba por la legitimación divina de la summa potestas del monarca-papal —concepción descendente del poder y del Derecho- - para que gobernara las esferas temporal y espiritual según los preceptos y dogmas cristianos:

«Hay dos espadas: la espiritual y la temporal [...] Una y otra espada, pues, están en la potestad de la Iglesia, la espiritual y la material. Mas ésta ha de esgrimirse en favor de la Iglesia; aquélla por la Iglesia misma. Una por mano del sacerdote, otra por mano del rey y de los soldados, si bien a indicación y consentimiento del sacerdote. Pero es menester que la espada esté bajo la espada y que la autoridad temporal se someta a la espiritual. Que la potestad espiritual aventaje en dignidad y nobleza a cualquier potestad terrena hemos de confesarlo con tanta más claridad, cuanto aventaja lo espiritual a lo temporal [...] Porque, según atestigua la Verdad, la potestad espiritual tiene que instituir a la temporal y juzgarla si no fuere buena $[\ldots]$ Luego si la potestad terrena se desvía será juzgada por la potestad espiri-

Actas del II Simposium de Historia de la Administración, Madrid, IEA, 1971, pp. 289-306, y F. TOMÁs y VALIENTE, «El gobierno de la monarquía y la administración de los reinos en la España del siglo XviI», en J. M. ${ }^{a}$ Jover Zamora (dir.), Historia de España de Menéndez Pidal, t. XXV, La España de Felipe IV. El gobierno de la monarquía, la crisis de 1640 y el fracaso de la hegemonía europea, Madrid, Espasa-Calpe, 1982.

${ }_{19}$ F. L. GANSHOF, El feudalismo, Barcelona, Ariel, 1985, p. 29.

${ }^{20}$ P. Grossi, El orden jurídico medieval, trad. de F. Tomás y Valiente y C. Álvarez, Madrid, Marcial Pons, 1996, p. 25.

${ }^{21}$ Cfr. Epistola de San Pablo a los Romanos (Rom. 13, 1-7). 
tual; si se desvía la espiritual menor, por su superior; mas si la suprema, por Dios sólo, no por el hombre, podrá ser juzgada» ${ }^{22}$.

El Derecho estaba determinado por la fe. El papa era la fuente material del Derecho: la única autoridad teológica legitimada por su ciencia para interpretar las Sagradas Escrituras, de acuerdo con el juicio omnipotente de Dios, en orden a regular los asuntos temporales y espirituales de conformidad con los principios de la fe y así lograr la finalidad celestial: la salvación del alma y la vida eterna ${ }^{23}$.

La consecuencia jurídica de esta caracterización de la naturaleza de la ley era que vinculaba a todos: «Concebida como una norma de un contenido objetivo y racional —en el sentido escolástico de esta palabra- [...] no cabía duda de que normas de tan inconmovible base y tan alto origen tenían que quedar por encima de todos, incluido también el príncipe» ${ }^{24}$.

El rey castellano Alfonso X el Sabio, imbuido por el Derecho romano justinianeo, fue refractario a esta concepción objetiva de la ley. Consideraba que la potestad legislativa definía la soberanía, por lo que pretendió reformar el sistema de fuentes del Derecho situando en su cúspide dos cuerpos normativos de alcance general en todo el reino: las Partidas y el Espéculo. La finalidad era robustecer el poder central del monarca - la unidad política - debilitando los poderes locales periféricos (nobles y burgueses) por medio de la unificación jurídica ${ }^{25}$. Sin embargo, las ciudades se opusieron en las Cortes a la obra alfonsina y lograron desactivar la refor-

22 Bula Unam Sanctam (1302) del papa Bonifacio VIII, citada por E. DENZINGER, El magisterio de la Iglesia. Manual de los símbolos, definiciones y declaraciones de la Iglesia en materia de fe y costumbres, Barcelona, Herder, 1963, pp. 170 y 171.

${ }^{23}$ Cfr. W. Ullmann, Principios de gobierno y política en la Edad Media, Madrid, Alianza Editorial, 1985, e ÍD., Historia del pensamiento político en la Edad Media, Barcelona, Ariel, 1983.

24 J. A. Maravall, Estado moderno y mentalidad social, t. I, Madrid, Alianza Editorial, 1972, p. 380.

${ }^{25}$ «La transcendencia histórica del redescubrimiento de la potestad legislativa es inmensa. El Derecho deja de ser donum Dei y legado de la tradición para convertirse en producto humano moldeable por la voluntad del poder, susceptible de ser manipulado y rectificado por el legislador. La ley es el mecanismo de producción de normas que posee mayor y más inmediata virtualidad transformadora de la realidad a la vez que, por mor de su generalidad, superior capacidad para equiparar a las personas y reducir o anular la disparidad de sus estatutos jurídicos. El privilegio diferencia, la ley iguala; aquél exime del régimen común, ésta rige para “todos comunalmente”»(B. GONZÁLEZ ALONSO, «Poder regio, Cortes y régimen político en la Castilla bajomedieval», en Las Cortes de Castilla y León en la Edad Media. Actas del Congreso sobre las Cortes de Castilla y León en la Edad Media, vol. II, Valladolid, Cortes de Castilla y León, 1989, p. 210). 
ma, sin cuestionar la competencia regia para dictar normas jurídicas, conservando la preeminencia del Derecho local:

«Para los castellanos a caballo entre los siglos XIII y XIV y para sus procuradores [el Derecho heredado] era el formado por la amalgama de fueros, costumbres y privilegios por los que se venían rigiendo generación tras generación. El Derecho por antonomasia es el "fuero", y el fuero es, por definición, Derecho singular, privilegio, ordenamiento peculiar y privativo de tal o cual población, de tales o cuales personas o sectores sociales. Para los procuradores, presentes en las sesiones de las Cortes en su condición de vecinos de las ciudades convocadas, el Derecho por excelencia es el amasado en los municipios, es decir, el integrado por el conjunto de los ordenamientos locales» ${ }^{26}$.

En la alborada del siglo XVI, Bodino define la soberanía como el «poder absoluto y perpetuo de una República» ${ }^{27}$. Hobbes coincide al afirmar que la soberanía — «alma del Estado»— ${ }^{28}$ implica un poder supremo o absoluto: «El rey cuyo poder es limitado no es superior a aquel o aquellos que tienen el poder para limitarlo, y quien no es superior no es supremo, esto es, no es soberano» ${ }^{29}$.

Los teóricos del absolutismo monárquico formularon una concepción subjetivista de la ley que desplazó a la medieval al hacerla depender directamente de la voluntas regis. La potestad legislativa era el principal atributo de la soberanía ${ }^{30}$ y la ley, norma suprema del sistema de fuentes del Derecho $^{31}$, ya no era el trasunto del Derecho divino, sino que debía estar al servicio de la razón de Estado:

«El legislador en todos los Estados es sólo el soberano, ya sea un hombre como en la monarquía o una asamblea de hombres como en una demo-

${ }^{26}$ Ibid., pp. 216 y 217.

27 J. BoDino, Los seis libros de la República, I, 8.

28 T. Hobbes, Leviatán, II, 22.

${ }^{29}$ Ibid., II, 19.

30 «El primer atributo del príncipe soberano es el poder de dar leyes a todos en general y a cada uno en particular [...] sin consentimiento del superior, igual o inferior [...] Bajo este mismo poder de dar y anular la ley están comprendidos todos los demás derechos y atributos de la soberanía, de modo que, hablando en propiedad, puede decirse que solo existe este atributo de la soberanía» (J. Bodino, Los seis libros de la República, I, 10).

31 «La ley puede anular las costumbres, pero la costumbre no puede derogar la ley [...] la costumbre solo tiene fuerza por tolerancia y en tanto que place al príncipe soberano, quien puede convertirla en ley mediante su homologación» (ibid., I, 10). 
cracia o aristocracia. Porque el legislador es el que hace la ley, y el Estado sólo prescribe y ordena la observancia de aquellas reglas que llamamos leyes: por tanto, el Estado es el legislador. Pero el Estado no es nadie ni tiene capacidad de hacer una cosa, sino su representante (es decir, el soberano), y, por tanto, el soberano es el único legislador. Por la misma razón, nadie puede abrogar una ley establecida sino el soberano, ya que la ley no es abrogada sino por otra ley que prohíbe ponerla en ejecución» ${ }^{32}$.

El poder absoluto de dictar leyes no incluía su interpretación, salvo supuestos excepcionales: «Cuando es tan oscura que los magistrados descubren contradicción o consecuencias absurdas e intolerables respecto de los casos contemplados». La facultad hermenéutica correspondía a los magistrados «siempre que se guarden mucho de quebrarla, aunque les parezca demasiado dura» ${ }^{33}$, en orden a impedir que socavaran la autoridad real y sometieran al pueblo a su voluntad:

«Convienen nuestros juristas en que esa ley nunca puede ser contra razón; afirman también que la ley no es la letra (es decir, la construcción legal), sino lo que está de acuerdo con la intención del legislador [...] la razón del Estado, nuestro hombre artificial, y sus mandamientos [es] lo que constituye la ley. Y siendo el Estado, en su representación, una sola persona, no puede fácilmente surgir ninguna contradicción en las leyes, y cuando se produce, la misma razón es capaz, por interpretación o alteración, de eliminarla. En todas las Cortes de justicia es el soberano (que personifica el Estado) quien juzga. Los jueces subordinados deben tener en cuenta la razón que motivó a su soberano a instituir la ley, a la cual tienen que conformar su sentencia; de otro modo es la suya propia, y una sentencia injusta $\left[\right.$ razón privada]» ${ }^{34}$.

\section{LA SOBERANÍA DE LA COSTUMBRE VERSUS LA SOBERANÍA DE LA LEY}

La Escuela Boloñesa osciló desde una posición de rechazo de la costumbre como fuente normativa (Irnerio), en orden a preservar la hegemonía del Derecho romano justinianeo, hacia otra más coherente con el pasado histórico.

\footnotetext{
32 T. HobBes, Leviatán, II, 26.

33 J. Bodino, Los seis libros de la República, I, 10.

34 T. HobBes, Leviatán, II, 26.
} 
Azón y Acursio resolvieron, por vía interpretativa, la contradicción de dos pasajes de la Compilación Justinianea referidos a la costumbre: una Ley de Juliano - De quibus - que empoderaba al pueblo al declarar la validez de la costumbre contra legem: «No sin razón se guarda como ley la costumbre inveterada, y éste es el Derecho que se dice establecido por la costumbre, porque así como las mismas leyes por ninguna otra causa nos obligan, sino porque fueron admitidas por la voluntad del pueblo, así también con razón guardarán todos lo que sin estar escrito aprobó el pueblo; porque, ¿qué importa que el pueblo declare su voluntad con votos, o con las mismas cosas y con hechos?, por lo cual también está perfectísimamente admitido que las leyes se deroguen no sólo por el voto del legislador, sino también por el tácito consentimiento de todos por medio del desuso» ${ }^{35}$; y una Constitución de Constantino que negaba tal posibilidad: «No es despreciable la autoridad de la costumbre y del uso de largo tiempo, pero no ha de ser válida hasta el punto de que prevalezca sobre la razón o sobre la ley» ${ }^{36}$.

La armonización jurídica realizada por los glosadores «pasó por reconocer pleno valor al texto del Digesto y por considerar que la Constitución de Constantino impedía que una costumbre especial derogase una ley general, pero no que una costumbre general pudiese prevalecer sobre una ley general» ${ }^{37}$.

La forma política del Medievo fue la monarquía dualista estamental, caracterizada por la dialéctica rey-reino, en la que laten dos elementos antagónicos, a saber, el teocrático (voluntas principis) y el feudal (pactum).

La faceta teocrática del rey implicaba que el pueblo le había sido encomendado por Dios para asegurar la paz y el orden público, sin que existiera relación o vínculo jurídico entre ambos. Las medidas político-legislativas eran decididas e impuestas por el arbitrio del monarca — quod principi placuit, habet legis vigorem - sin el concierto ni la anuencia de los privilegiados de la sociedad medieval: concepción teocrática del gobierno y del Derecho. La voluntas rei era expresión de la vox dei y no existía ninguna instancia que limitara o constriñera su poder absoluto.

En cambio, la faceta feudal implicaba una relación contractual entre el monarca y los barones, de la que se derivaban importantes consecuencias. La concepción feudal del Derecho entrañaba limitaciones al poder real: protección de la propiedad privada, garantías procesales y la prohi-

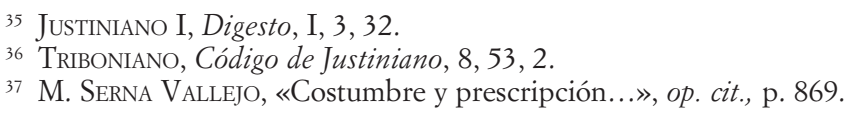


bición de la imposición de tributos por el rey. Así pues, la promulgación de leyes no podía ser acordada por la autoridad regia, sino que necesariamente tenía que ser fruto del pactum entre el monarca y los prebostes, que actuaban en nombre de la comunidad.

El resultado de varios siglos de enfrentamientos arrojó una suerte dispar a los contendientes según los países: en España y Francia se impuso el monarca teocrático sobre los estamentos, lo que dio lugar a la monarquía absoluta basada en la soberanía personal del rey; en Inglaterra, en cambio, venció el reino, representado por la Cámara de los Comunes y la de los Lores, lo que alumbró un gobierno mixto fundado en la soberanía del Parlamento - Rey y Lores y Comunes - y el consecuente principio de legalidad (rule of law) ${ }^{38}$. Como señala Varela Suances, «tal diferencia en la fundamentación doctrinal de la monarquía tenía su correlato en el ámbito institucional: mientras en España apenas se convocaron Cortes durante esos siglos [XVI y XVII] y en Francia los Estados Generales dejaron de convocarse en 1614, las Cámaras de los Lores y de los Comunes siguieron manteniendo su presencia política durante esa época a pesar del indudable reforzamiento del poder regio durante la época de los Tudores y Estuardos» ${ }^{39}$ :

«Mientras en la mayoría de los países continentales la concentración (de poder) tuvo lugar en manos del monarca, en Inglaterra se verificó en el Parlamento. La variación es primordialmente de titular, pero no de calidad de poder: al igual que el monarca continental, el Parlamento se hizo supremo, no ligado al Derecho anterior, sino superior a él; de la misma manera que en el continente se conservaron, a veces, formalmente las Cortes o los Estados Generales, pero quedando subordinados al monarca, de la misma manera, pero al revés, en Inglaterra el monarca quedó finalmente subordinado al Parlamento, hasta el punto de poderse definir la prerrogativa como el remanente de poder que el Parlamento ha dejado al rey» ${ }^{40}$.

${ }^{38}$ La prevalencia del régimen feudal sobre el teocrático en Inglaterra fue debido al vínculo jurídico establecido entre el rey y su curia —los nobles y el clero-, plasmado en la Carta Magna de 1215, en virtud de la cual se redujo sensiblemente la faceta teocrática del rey en la creación del Derecho y se consagró la vigencia de la lex terrae o Derecho feudal: «El derecho que incorporaba en sí toda la esencia del feudalismo y, en especial, el elemento contractual: el derecho elaborado con el consentimiento (expreso o implícito) de los barones constituía el derecho a ser aplicado por los tribunales de los pares» (W. Ullmann, Principios de gobierno..., op. cit., pp. 167 y 168).

39 J. Varela SuAnces, «La soberanía en la doctrina británica (de Bracton a Dicey)», Fundamentos, núm. 1 (1998), p. 92.

${ }^{40}$ M. García-Pelayo, Derecho Constitucional Comparado, Madrid, Alianza Editorial, 1984, pp. 250-251. 
Durante el Antiguo Régimen tuvo lugar en la Europa continental la historia jurídica de Inglaterra fue diferente- ${ }^{41}$ un enconado enfrentamiento dialéctico y social sobre las fuentes formales del Derecho - ley y costumbre - porque estaba en juego nada menos que la determinación del centro de imputación del poder político: la titularidad de la soberanía.

De una parte estaban el emperador, el papa y los reyes, que defendían la «tesis romana de que la ley y el Derecho son creaciones de una voluntad legisladora que actúa consciente y deliberadamente, ya sea la voluntad de un gobernante particular o de una determinada comunidad»; y la otra parte estaba representada por los señores feudales y las ciudades, que sostenían que «el Derecho no trae su existencia de un acto creador de la voluntad, sino que se concibe como un aspecto de la vida colectiva, como costumbre; el acto legislativo no es manifestación de una voluntad normativa, sino simple redacción o plasmación escrita de cuanto ya vive como Derecho en el uso y costumbre de sus hombres» ${ }^{42}$ :

«No en vano si el emperador, los reyes, el papa y sus respectivos juristas defendían la supremacía de la ley respecto del Derecho consuetudinario y luchaban por limitar las costumbres, en particular las contrarias a la ley, lo hacían porque el reconocimiento de la superioridad de aquélla implicaba la consolidación de su propio poder y autoridad, mientras que la defensa que los feudistas, las ciudades y las comunidades eclesiásticas locales formularon de la costumbre se explica en el interés que tenían en preservar su autonomía y fuerza frente al emperador, a los reyes y al papa» ${ }^{43}$.

Esta controversia se suscitó también en España entre juristas y teólogos. Los primeros admitían la costumbre contra legem porque «el soberano tiene su autoridad dependiente del pueblo, y por eso no puede promulgar una ley sino a condición de que el pueblo la acepte, y que el pueblo puede legítimamente abstenerse de aceptar, o sea, de cumplir una ley y

${ }^{41}$ «El derecho emanado del rey y sus barones se componía primordialmente de costumbres no escritas, algunas muy antiguas, que el rey y su curia más que aprobar se limitaban a confirmar [...] era el derecho quien hacía al rey y no a la inversa [...] [sin embargo] a lo largo del siglo XVII los jueces de Common Law se vieron obligados a aceptar, no sin renuencia, la supremacía de los statutes aprobados por el Parlamento, a cambio de que éste reconociese la importancia del Derecho consuetudinario en el sistema de fuentes» (J. VARELA SUANCES, «La soberanía en la doctrina británica...», op. cit., pp. 89 y 100).

42 A. Passerin d'Entrèves, La noción del Estado, Barcelona, Ariel, 2001, p. 103.

${ }_{43}$ M. SeRna Vallejo, «Costumbre y prescripción...», op. cit., p. 875. 
desusar la que una vez aceptó [...] el rey es el órgano de la legislación, el pueblo es el señor del Derecho, por donde, si una ley no le conviene, la desusa y se da otra así propio en forma de costumbre».

Los segundos, en cambio, sostenían que «introducir costumbre y constituir ley es una misma cosa, dado que aquélla tiene la misma fuerza que ésta; por consiguiente, los que pretenden que el pueblo puede en un Estado monárquico abrogar una ley por una costumbre contraria no sólo suponen al pueblo potestad legislativa; suponen que esa potestad del pueblo es superior a la del soberano, y esto es absurdo, porque vale tanto como suponer que el inferior tiene potestad sobre el superior, tanto como suponer que una misma cosa es juntamente superior e inferior. Los que no ven este defecto de potestad en los pueblos sujetos a monarca, lo tienen en su entendimiento, o acaso en su voluntad, no queriendo verle» ${ }^{44}$.

Esta disputa por la soberanía propició en España un divorcio entre el poder político absolutista, que promulgaba una miríada de leyes, y el pueblo, que las inobservaba sistemáticamente — «se acatan pero no se cumplen»aplicando en su lugar las costumbres locales ${ }^{45}$. Felipe II en 1593 y Felipe III en 1610 advirtieron estérilmente al Reino de los efectos inicuos que se habían derivado del incumplimiento sistemático de las pragmáticas reales:

«Como quiera que para el buen gobierno y administración de justicia destos nuestros Reynos se han proveído y promulgado diversas leyes y pragmáticas, cuya observancia ha sido y es muy importante y necesaria, y no la han tenido como conviene, lo cual ha procedido así del poco cuidado que de su execución y de las penas por ellas impuestas han tenido las nuestras Justicias, como de haberse usado de diversos medios e invenciones para defraudar lo por ellas proveído; de que, además de haber sido Nos deservido, han resultado grandes daños e inconvenientes, que requieren breve y eficaz remedio; y habiéndose conferido y platicado sobre ello en el nuestro Consejo y con Nos consultado, fue acordado que debíamos mandar y mandamos por esta nuestra ley y pragmática sanción, la qual queremos que haya fuerza y vigor de ley, como si fuese fecha y promulgada

${ }^{44}$ J. Costa, El problema..., op. cit., pp. 87-89.

${ }_{45}$ «Cuando se analiza la vida interna de la nación en aquellas dos centurias, particularmente la de su legislación, no tarda en formarse la impresión de una sociedad sin Estado o, si se quiere, de un Estado de papel, vacío de todo contenido, en que el monarca y el pueblo se disputan calladamente la soberanía y la ejercen ambos a la vez, no armónicamente y de concierto, sino en oposición y por vía de resta: el primero, escribiendo sus tablas de preceptos y declaraciones y notificándoselas pomposamente, cual desde otro Sinaí, al pueblo; el pueblo, oponiéndoles su veto pasivo, negándoles su sanción» (ibid., p. 113). 
en Cortes, que de aquí en adelante se guarden las leyes contenidas en los nueve libros de la Recopilación de las Leyes destos Reynos» ${ }^{46}$.

El propio Felipe $V$ tronó en 1714 contra los doscientos años de desuso popular de las leyes del Reino, reiterando su vigencia y su carácter vinculante para todos los súbditos:

«Todas las leyes del Reyno que expresamente no se hayan derogado por otras posteriores se deben observar literalmente, sin que quepa admitirse la excusa de decir que no están en uso, pues así lo ordenaron los Señores Reyes Católicos y sus sucesores en repetidas leyes y yo lo tengo mandado en diferentes ocasiones; y aun cuando estuviesen derogadas, es visto haberlas renovado por el decreto que conforme a ellas expedía, aunque no las expresase; sobre lo qual estará advertido el Consejo, celando siempre la importancia de este asunto» ${ }^{47}$.

Para garantizar la seguridad jurídica y la prueba de la costumbre ante los tribunales ${ }^{48}$, era práctica habitual en las tierras castellanas proceder periódicamente a la actualización, concreción y definición de las mismas mediante su promulgación en ordenanzas locales por los vecinos de la localidad (concejo abierto) ${ }^{49}$ o en fueros aprobados por los representantes del Reino: Fueros de Vizcaya (Junta General del Señorío) u Observancias de Aragón (Cortes aragonesas):

«La costumbre no fue general ni coincidente para todos los reinos y ni siquiera fue la misma para un solo reino, sino que el ámbito de su vigencia territorial fue en muchas ocasiones muy reducido; por ejemplo, una localidad y sus términos circundantes. También existieron costumbres con vigencia territorial mezcladas con las locales» ${ }^{50}$.

La aplicación de la costumbre por los tribunales locales protegía los derechos tradicionales del vulgo sobre las tierras comunales y baldías, cuya subsistencia se veía gravemente amenazada por las pretensiones de

${ }^{46}$ Novísima Recopilación, Lib. III, Tít. II, Ley 10.

${ }^{47}$ Ibid., Lib. III, Tít. II, Ley 11.

${ }^{48}$ Cfr. M. ${ }^{a}$ J. Monsalvo Antón, «Costumbres y comunales en la tierra medieval de Ávila (observaciones sobre los ámbitos del pastoreo y los argumentos rurales en los conflictos de términos)», en S. DE Dios et al. (coords.), Historia de la propiedad, costumbre y prescripción, Madrid, Servicio de Estudios del Colegio de Registradores, 2006, pp. 15-70.

${ }^{49}$ Cfr. J. Costa, El problema..., op. cit., pp. 122-130.

50 J. M. Pérez-Prendes, Curso de Historia..., op. cit., p. 503. 
la nobleza y la burguesía, que ambicionaban privatizarlas y robustecer el derecho de propiedad con el fin de impedir cualquier uso o aprovechamiento comunitario mediante el cercamiento de los predios:

«La masa de la población, compuesta de los débiles, de los desheredados, de los imprevisores, de los poco capaces, de las familias heridas por la muerte en los miembros que habían de servirles de sostén, las que sucumbían a los rigores de la fortuna, a accidentes fortuitos de la naturaleza, a desgracias imprevistas, encontraban en esas instituciones un alivio para su desventura, o una tutela contra el egoísmo de los afortunados; con ellas, la competencia tenía un regulador y la lucha por la existencia un freno. No abarcaban la vida entera, que habría sido oprimir o negar la individualidad; le servían de coeficiente en el límite preciso, y nada más; regularizaban y moderaban el movimiento no siempre ordenado de ese mecanismo complejo de la vida local, donde tantas fuerzas se cruzan, entrechocan y destruyen» ${ }^{51}$.

El desenlace de la pugna entre la soberanía de la costumbre (soberanía popular) y la soberanía de la ley (soberanía personal del monarca) se produjo con la Revolución Francesa, que inauguró la ideología constitucional. El constitucionalismo de primera hora - netamente liberal— se caracterizaba por la garantía de la libertad y de la igualdad de los ciudadanos mediante la institución de nuevos principios políticos — división de poderes y soberanía nacional - y jurídicos: legalidad, seguridad jurídica y responsabilidad e interdicción de la arbitrariedad de los poderes públicos.

La naturaleza legista del ordenamiento jurídico burgués, cifrada en la primacía y omnipotencia de la ley ${ }^{52}$, fue posible gracias al carácter programático de las Constituciones liberales - pacto político entre el rey (principio monárquico) y las Cortes (principio representativo)_, vigente hasta el siglo $\mathrm{xx}^{53}$, de forma que la igualdad ante la ley, la seguridad jurídica, la

\footnotetext{
${ }^{51}$ J. Costa, Derecho consuetudinario y economía popular de España, t. I, Zaragoza, Guara, 1981, p. 319.

52 «La primacía o preeminencia de la ley significa que todas las demás fuentes se encuentran subordinadas a ella, careciendo de un ámbito de normación autónomo [...] La omnipotencia de la ley hace referencia a su carácter incondicionado, a la ausencia de límites que vinculen al legislador. Se trata, en otros términos, de la inexistencia de una auténtica supralegalidad constitucional jurisdiccionalmente garantizada» [M. L. DíEz PICAzo, «Concepto de ley y tipos de leyes. ¿Existe una noción unitaria de ley en la Constitución española?», Revista Española de Derecho Constitucional, núm. 24 (1988), p. 49].

Sobre el concepto formal de ley, acuñado por el primer constitucionalismo liberal, cfr. C. DE CABo, Sobre el concepto de ley, Madrid, Trotta, 2000, pp. 29-35.

${ }_{53}$ Mientras que en Estados Unidos la Constitución fue la norma suprema del ordenamiento jurídico desde su aprobación en 1787 (el art. VI.2 la declara «Ley Suprema del
} 
racionalización del poder político y el embrionario estatuto jurídico del ciudadano fueron obra de la ley.

Las revoluciones liberales, impulsadas por el iusnaturalismo racionalista, abatieron a radice el Antiguo Régimen e instituyeron el absolutismo parlamentario (soberanía del Parlamento). En efecto, la soberanía nacional proclamada en la Constitución francesa de 1791 no fue más que un principio huero al estatuir una dicotomía en la titularidad de los derechos políticos: elector y ciudadano activo ${ }^{54}$. Así pues, el sufragio censitario excluyó a la inmensa mayoría de la población - ciudadanos pasivos- de la participación efectiva en la vida política y propició la constitución de un Parlamento burgués.

El principio de soberanía nacional fue un efectista reclamo propagandístico durante el periodo revolucionario para lanzar a las masas desposeídas contra la monarquía absolutista en beneficio de la burguesía, que aprovechó la coyuntura propicia, generada por el desmoronamiento del régimen monárquico-señorial, en orden a lograr el objetivo que pretendían alcanzar desde hacía siglos: asumir la dirección política del Estado:

«En Hobbes el pactum subiectionis confiere todo el poder al soberano, que no está sometido a ningún vínculo; en realidad, se daba una identificación del monarca con el pueblo y con el Estado, los cuales no tenían, según Hobbes, una voluntad distinta de la de aquél. Pues bien, los revolucionarios franceses terminaron haciendo lo mismo, sólo que sustituyendo parcialmente al rey por el Parlamento, cuya voluntad —la ley— se identificaba con la voluntad general, es la voluntad general; ésta no puede ser otra cosa que la voluntad manifestada por los representantes» ${ }^{55}$.

Las Cortes dejaron atrás la edad de hierro, caracterizada por su irrelevancia jurídico-política, y vivieron un periodo áureo en el que ocuparon la centralidad institucional del Estado. Se convirtieron en el vértice de la acción política de la nación, ya que, por una parte, tenían el monopolio de

país»), en la Europa continental fueron las Constituciones alemana (1919) y austríaca (1921) las que reconocieron por primera vez la naturaleza jurídica de la Constitución y su carácter de norma suprema, desplazando y subordinando a la ley.

Sobre la quiebra del concepto tradicional de ley provocado por la normatividad constitucional, cfr. C. DE CABO, Sobre el concepto..., op.cit., y M. L. Díez PiCAZO, «Concepto de ley...», op. cit. 1791.

${ }^{4}$ Cfr. título III, capítulo I, sección II, arts. 2, 5 y 7, de la Constitución francesa de

55 A. TORRes Del Moral, «Crisis del mandato representativo en el Estado de partidos», Revista de Derecho Político, núm. 14 (1982), p. 10. 
la potestad normativa ${ }^{56} \mathrm{y}$, por otra, la ley fue encumbrada como «manifestación directa de la razón jurídica» ${ }^{57}$ y puesta al servicio de los intereses de la burguesía — «quod oligarchae placuit, legis habet vigorem» ${ }^{58}$ —, cuyos representantes señoreaban la asamblea legislativa:

«La escuela no histórica admite que el Derecho puede ser creado en cada momento por el arbitrio de las personas investidas del poder legislativo, con completa independencia del Derecho de los tiempos pasados y solamente según sus convicciones, tal y como las produce el presente momento histórico. Así, esta escuela no puede explicar el que en alguna ocasión no sea todo el Derecho introducido completamente nuevo y diverso del precedente, sino porque el legislador fue perezoso en el recto ejercicio de su cargo y tuvo, por tanto, necesidad de conservar, aunque con carácter de interinidad, como verdaderas para el presente, las opiniones jurídicas del momento anterior» ${ }^{59}$.

Desde finales del siglo xvIII, los Parlamentos y ayuntamientos convirtieron la maximización de los beneficios burgueses en razón de Derecho mediante la aprobación de leyes de cercamiento de predios ${ }^{60}$ — concepción absolutista de la propiedad- ${ }^{61}$ y la desamortización de las tierras municipales y baldías para entregárselas a sus iguales a precios muy ventajosos:

56 Las Constituciones francesas de 1791 y la non nata de 1793 no reconocieron la potestad reglamentaria al poder ejecutivo. Será la Constitución de 1795 la que atribuya por primera vez al gobierno la facultad de aprobar reglamentos para garantizar la aplicación de las leyes. Cfr. F. L. Hernández GonzÁlez, «La evolución de la potestad reglamentaria en el constitucionalismo francés. Mitos y realidades», Revista de Administración Pública, núm. 163 (2004), pp. 468 y 469.

57 B. Castro CID, «El nacimiento de las normas jurídicas», en N. MarTínEz Morán y B. Castro Cid, Diecisiete lecciones de Teoría del Derecho, Madrid, Universitas, 2010, p. 90, nota 15 .

58 J. Costa, Oligarquía y caciquismo, Madrid, Establecimiento Tipográfico de Fortanet, 1902 , p. 27.

59 F. K. VON SAVIGNY, «Sobre el fin de la Revista de la Escuela Histórica...», op. cit., p. 16.

${ }^{60}$ «El cercamiento arruinaría a Inglaterra; era peor que diez guerras [...] Yo tenía cuatro vacas antes de que la parroquia fuera cercada y ahora no tengo ni tan sólo un ganso [manifestación realizada por un cottage en 1804 en Maulden (Bedfordshire), cuyo terreno comunal fue cercado en 1797]» (E. P. Thompson, Costumbres en común, Barcelona, Crítica, 1995, p. 205).

«En 1791 en Sheffield se había aprobado un ley especial para cercar seis mil acres (2.430 hectáreas) de tierra comunal y baldía junto a la ciudad, compensando a los pobres con dos acres $(0,809$ hectáreas) solamente» (ibid., p. 147).

61 Art. 544 del Código Civil napoleónico (1804): «La propiedad es el derecho de gozar y disponer de las cosas de la manera más absoluta, con tal que no se haga un uso de las mismas prohibido por las leyes o los reglamentos». 
«La economía individualista y atómica, basada en categorías abstractas de razón, y el espíritu revolucionario de nuestro siglo, impulsado por un odio ciego a lo pasado, destruyeron en una hora la más de esas fórmulas, que venían consagradas por el voto de treinta generaciones, y entorpecieron el juego de las demás, y el campesino y el menestral se han encontrado repentinamente abandonados a sí propios, huérfanos de aquella tutela paternal que los antepasados habían encarnado en instituciones sabias y protectoras, solos enfrente de un Estado central incapaz de prevenir los dolores individuales y aun de remediarlos de otro modo que por el incompleto e imperfectísimo de la beneficencia pública organizada militarmente» ${ }^{62}$.

El imperio de la ley fue concebido de forma extrema por los revolucionarios franceses. La ley no precisaba de otros productos normativos complementarios $^{63}$ o de técnicas hermenéuticas ${ }^{64}$ —iuspositivismo jurídico- ${ }^{65}$ para satisfacer la plenitud del ordenamiento jurídico. ¿Cuál fue el motivo? La desconfianza hacia la nobleza de la toga, adicta a Luis XVI y renuente a perder sus inveterados privilegios, ya que existía el riesgo de que socavaran las reformas revolucionarias en la aplicación de la ley.

La primacía y omnipotencia de la ley se consagraron definitivamente gracias a la codificación. El movimiento codificador europeo produjo la perfecta identificación entre Derecho y ley porque su fuerza expansiva cegó cualquier espacio de vigencia a la costumbre. La unificación jurídica actuó como palanca de la unidad política, ya que redujo la pluralidad de fuentes materiales y formales del Derecho a una: el Parlamento y la ley ${ }^{66}$. Asimismo, la codificación garantizó la seguridad jurídica mediante la ordenación y sistematización del pandemónium legislativo del Antiguo Régimen ${ }^{67}$ y prestó

62 J. Costa, Derecho consuetudinario..., op. cit., p. 319.

63 «El poder ejecutivo no puede hacer ninguna ley, ni siquiera provisional, sino únicamente proclamaciones conforme a las leyes para ordenar o recordar su ejecución» (título III, capítulo IV, sección I, art. 6, de la Constitución de 1791). En similares términos se pronuncia el art. 65 de la Constitución de 1793.

64 «Los jueces de la Nación, como es sabido, no son ni más ni menos que la boca que pronuncia las palabras de la ley, seres inanimados que no pueden mitigar la fuerza y el rigor de la ley misma» (Montesquieu, El espíritu de las leyes, XI, 6).

${ }^{65}$ Cfr. H. KeLSEN, «¿Qué es el positivismo jurídico?», Revista de la Facultad de Derecho de México, núm. 61 (1966).

${ }^{66}$ Cfr. E. Gómez Arboleya, «El racionalismo jurídico y los Códigos europeos», Revista de Estudios Políticos, núms. 57 (1951), 60 (1951) y 63 (1952), y N. PÉrez SERrano, «Constitucionalismo y codificación», Revista General de Legislación y Jurisprudencia, t. XXV, núm. 193 (1953), pp. 92-104.

${ }^{67}$ Cfr. F. Martínez Marina, Juicio crítico a la Novísima Recopilación, Madrid, Fermín Villalpando, 1820. 
un encomiable servicio en favor de la igualdad formal ante la ley en la esfera pública —Código Penal y Procedimiento Penal—y privada —Códigos Civil y Mercantil y Procedimiento Civil— ${ }^{68}$.

68 «La Codificación es una aspiración de los nuevos regímenes liberales y el modo de exteriorizar la afirmación de los derechos individuales del ciudadano frente al nuevo Estado. Por esta razón, la Codificación persigue la unificación del Derecho y la supresión de la desigualdad entre los ciudadanos; el principio constitucional de la igualdad adquiere su consagración en el orden del Derecho privado a través de los Códigos Civiles y Mercantiles, que además confieren garantías suficientes para el ejercicio de esos derecho erga omnes» [J. BARÓ Pazos, La codificación del Derecho Civil en España (1808-1889), Santander, Universidad de Cantabria, 1993, p. 13]. 